\title{
Reproductive costs in Acer saccharum: exploring size- dependent relations between seed production and branch extension
}

\author{
Shaik Md. Yousuf Hossain, John P. Caspersen \& Sean C. Thomas
}

Version Post-Print $\backslash$ Accepted Manuscript

Citation Hossain, S.M.Y., Caspersen, J.P. \& Thomas, S.C. Reproductive costs in Acer

(published saccharum: exploring size-dependent relations between seed production and

version) branch extension. Trees 31, 1179-1188 (2017).

https://doi.org/10.1007/s00468-017-1536-4

\begin{abstract}
Publisher Terms
1. Archived content may only be used for academic research. Any content

of Use downloaded for text based experiments should be destroyed when the experiment is complete.

2. Archived content may not be used for purposes that are intended for or directed towards commercial advantage or monetary compensation by means of sale, resale, licence, loan, transfer or any other form of commercial exploitation ("Commercial Purposes").

3. Archived content may not be published verbatim in whole or in part, whether or not this is done for Commercial Purposes, either in print or online.

4. This restriction does not apply to reproducing normal quotations with an appropriate citation. In the case of text-mining, individual words, concepts and quotes up to 100 words per matching sentence may be used, whereas longer paragraphs of text and images cannot (without specific permission from Springer Nature).

5. All use must be fully attributed. Attribution must take the form of a link - using the article DOI - to the published article on the journal's website.

6. All use must ensure that the authors' moral right to the integrity of their work is not compromised.

7. Where content in the document is identified as belonging to a third party, it is the obligation of the user to ensure that any use complies with copyright policies of the owner.

8. Any use of Springer Nature content is at your own risk and Springer Nature accepts no liability arising from such use.
\end{abstract}

How to cite TSpace items

Always cite the published version, so the author(s) will receive recognition through services that track citation counts, e.g. Scopus. If you need to cite the page number of the author manuscript from TSpace because you cannot access the published version, then cite the TSpace version in addition to the published version using the permanent URI (handle) found on the record page.

This article was made openly accessible by $U$ of $T$ Faculty. Please tell us how this access benefits you. Your story matters. 
1 Reproductive costs in Acer saccharum: exploring size-

2 dependent relations between seed production and branch

3 extension

4

5

6 Shaik Md. Yousuf Hossain ${ }^{1}$. John P. Caspersen ${ }^{1}$. Sean C. Thomas ${ }^{1}$

$7 \quad{ }^{1}$ Faculty of Forestry, University of Toronto, Toronto, Ontario, Canada

8

9 Corresponding author

10 Shaik Md. Yousuf Hossain

11 shaikhossain812@gmail.com

12

13

14

15 


\section{Abstract}

17 Key message: Branch extension of Acer saccharum is negatively correlated with seed

18 production, with no independent effect of tree size, consistent with reproductive

\section{9 allocation as the main driver of the age-related decline in tree canopy growth.}

21 Abstract Life-history theory predicts that reproductive allocation should increase with

22 age and size once plants reach reproductive maturity. This suggests that there may also be

23 a subsequent decline in somatic growth as plants become larger or older. However, few

24 studies have examined how the relationship between branch extension growth and

25 reproduction varies with size or age in the longest-lived plants: trees. Using a mobile lift

26 for canopy access, we retrospectively measured branch extension growth before, during

27 and after two (2011 and 2013) Acer saccharum mast events (the synchronous production

28 of many seeds at long intervals), quantifying seed production per internode and internode

29 length. Branch extension was reduced by $24 \%$ and $36 \%$, respectively, in 2011 and 2013

30 relative to non-mast years, consistent with the expectation that increased reproductive

31 allocation comes at the cost of allocation to growth. Internode length decreased from 8 to

$323 \mathrm{~cm}$ year $^{-1}$ as seed production increased from zero to 17 seeds year ${ }^{-1}$; a similar decrease

33 was observed at the whole-tree level using average internode extension rates and seed

34 production per tree. Seed production alone was the most parsimonious predictor of

35 branch extension growth, with no independent effect of tree size, suggesting that it is the

36 increase in reproductive allocation, rather than an increase in tree size per se, that drives

37 the decline in branch extension rates. The slope of the relationship between branch

38 extension and reproduction did not vary with tree size, suggesting that there was no 


\section{Page 3 of 37}

39 increase in the somatic cost of reproduction with tree size. We also found no evidence for

40 lag effects of reproduction on extension growth in subsequent years. Overall, these results

41 suggest that reproductive allocation assessed at the shoot level increases with tree size

42 and is a major driver of the ontogenetic decline in branch extension growth.

44 Keywords Acer saccharum . Allocation . Branch extension . Cost of reproduction .

45 Haliburton Forest . Internode. Trade-offs

46

47

48

49

50

51 


\section{Introduction}

53 Numerous studies have examined whether and why tree growth declines later in ontogeny

54 (Bond and Ryan 2000; Choi et al. 2001; Cole and Lorimer 2005; Ryan et al. 2006; Bond

55 et al. 2007; Stephenson et al. 2014). Two principal hypotheses have emerged from the

56 ecophysiology literature (Ryan et al. 1997). On the one hand, the largest body of

57 literature focuses on biophysical processes as the main drivers of growth decline. For

58 example, both height growth and branch extension have been hypothesized to be limited

59 by hydraulic conductance because the combined forces of gravity and friction increase as

60 trees grow taller and branches grow longer, thereby reducing hydraulic conductance and

61 increasing the risk of xylem cavitation (Koch et al. 2004). This in turn forces stomatal

62 closure and limits carbon dioxide diffusion into leaves, which leads to reduced

63 photosynthesis and potentially reduced growth (Barnard and Ryan 2003; Yoder et al.

64 1994; Gower et al. 1996). Alternatively, xylem tension may constrain the turgor pressure

65 of the uppermost leaves, thereby limiting cell expansion, intercellular diffusion of carbon

66 dioxide, and ultimately shoot extension (Woodruff et al. 2004; Ryan et al. 2006).

67 Although biophysical processes have received more attention, there is a smaller

68 body of literature that focuses on the role of reproduction in driving ontogenetic patterns

69 of tree growth. Life-history theory provides an important basis for predicting growth

70 declines based on the recognition that allocation of resources to competing biological

71 functions changes throughout ontogeny (Iwasa and Cohen 1989; Thomas 1996; Iwasa

72 2000; Thomas 2011). In particular, life-history theory asserts that reproductive allocation

73 increases with plant size due to switching of resources from vegetative tissues to

74 reproductive structures (King and Roughgarden 1982; Thomas 1996; Kelly and Sork 
75 2002; Obeso 2002; Genet et al. 2010). As a result, plants are expected to exhibit a

76 developmental trade-off between reproduction and growth, whereby growth declines as

77 reproduction increases (Gross 1972; Fox and Stevens 1991; Weiner and Thomas 2001;

78 Monks and Kelly 2006). Specifically, one would expect to observe a tradeoff at the level

79 of individual branches (Sanchez-Humanes et al. 2011), such as reduced growth of

80 branches that produce seeds during mast years, particularly if branches are independent

81 from other parts of the tree with regard to translocation of resources such as carbon and

82 nutrients (Dick et al. 1990; Sprugel et al. 1991; Despland and Houle 1997).

83 Reproductive costs have commonly been dismissed as playing an important role

84 in age-related growth decline, based on the argument that reproduction is often sporadic,

85 and thus unlikely to explain the continuous decline in tree growth (Gower et al. 1996;

86 Ryan et al. 1997; Bond and Ryan 2000; Bond et al. 2007; Kutsch et al. 2009). However,

87 several studies have reported that reproduction in prior years may have a significant

88 carry-over effect on the current year's growth and survivorship (Gross 1972; Woodward

89 et al. 1993; Silvertown and Dodd 1999). This suggests that despite being sporadic,

90 reproduction may entail a substantial reduction in tree growth as trees grow older

91 (Thomas 2010), particularly if seed production increases in frequency or intensity

92 through ontogeny (Thomas 2011), resulting in continual carry-over effects between

93 successive reproductive events.

94 Two lines of reasoning indicate that allocation to reproduction increases over the

95 lifespan of a tree. First, many species do not reproduce until they reach a threshold size,

96 even when light is not limiting, so there is no initial trade-off between reproduction and

97 growth (Thomas 2011; Thomas et al. 2015). Second, once reproductive maturity is 
98 attained, the frequency and output of reproduction often increase with tree size (Thomas

99 2011), suggesting an ontogenetic increase in allocation to reproduction as predicted by

100 life-history theory. Indeed, allocation of annual fixed carbon to reproductive structures is

101 reported to increase from $5 \%$ in small diameter $(<20 \mathrm{~cm} \mathrm{DBH})$ trees to over $40 \%$ in large

102 diameter trees (>20 cm DBH) of mature forests (Genet et al. 2010). This increase in

103 allocation to reproduction could be one of the primary drivers of the decline in tree

104 growth, including stem growth and branch extension (Obeso 2002).

105 It remains uncertain whether ontogenetic increases in reproductive allocation are

106 important in driving growth trends in mature trees. To date, direct evidence that increased

107 reproductive allocation reduces growth is largely limited to herbaceous plants (e.g.

108 Worley and Harder 1996), because it is relatively easy to conduct experiments on small

109 plants with shorter lifespans to study ontogenetic trends in growth and reproduction.

110 Although direct evidence for tradeoffs between reproduction and growth for trees is 111 scant, a tractable observational method that has been employed is to examine

112 relationships between branch extension growth and reproduction. Branch extension is

113 critical to tree resource capture and competition (Hibbs 1982; Cole and Lorimer 2005;

114 Purves et al. 2007; Thorpe et al. 2010), and therefore of at least comparable ecological

115 importance as stem diameter growth or biomass accumulation. A recent review found 116 that every prior study collecting such data showed a negative correlation between 117 reproduction and extension growth (Thomas 2011), suggesting that this pattern is 118 pervasive. However, most studies have not distinguished between branch-level and 119 whole-tree-level effects, and we are not aware of any prior research that has utilized 
120 observations on shoot extension - reproduction patterns to investigate age- and/or size-

121 related reproductive costs and their role in plant ontogeny.

122 In the present study we utilized a mobile canopy lift for canopy access to

123 retrospectively quantify seed production and branch extension in mature Acer saccharum

124 trees before, during, and after two mast events. These data are used to address the

125 following questions: (i) Is there a negative correlation between seed production and

126 branch extension? (ii) Does seed production per internode increase with tree size? (iii)

127 Does variation in seed production contribute independently to decreased internode

128 extension growth when one accounts for size-dependent growth? (iv) Does the

129 relationship between seed production and branch extension vary with tree size, such that

130 large trees show a higher apparent somatic cost of reproduction than smaller trees? and

131 (v) Is there evidence for temporally lagged effects of seed production on extension

132 growth? We addressed each of these questions at the level of individual branches, and

133 also at the level of entire trees, to determine whether the relationship between growth and

134 reproduction is mediated by local resource allocation.

\section{Methods}

\section{Study area and species}

139 The study area is located in south central Ontario at Haliburton Forest and Wildlife 140 Reserve $\left(45^{\circ} 15^{\prime} \mathrm{N}, 78^{\circ} 34^{\prime} \mathrm{W}\right)$, a 32,000-ha privately owned forest. The climate is 141 characterized by warm, wet summers and cold winters, with a mean annual precipitation 142 of $1000 \mathrm{~mm}$ and mean monthly temperature ranging from 18.9 in July to $-10.9^{\circ} \mathrm{C}$ in 
143 January (Environment Canada 2004). Sugar maple is the dominant tree species in this

144 tolerant hardwood forest, representing nearly $60 \%$ of basal area; other common species

145 include yellow birch (Betula alleghaniensis Britt.), American beech (Fagus grandifolia

146 Ehrh.), eastern hemlock (Tsuga canadensis (L.) Carr.), and balsam fir (Abies balsamea

147 L.). The forest has an uneven-aged structure, having been managed by selection

148 silviculture over last 40 years, with basal area and canopy height ranging from $15-30 \mathrm{~m}^{2}$

$149 \mathrm{ha}^{-1}$ and $20-25 \mathrm{~m}$, respectively.

150 Sampling occurred in 2011 and 2013, both of which were mast years when most

151 sugar maple trees produced seeds, with a smaller sample collected in 2015, a non-mast

152 year. Sugar maple exhibits sequential dichogamy, a reproductive system in which trees

153 are monoecious but with protandrous and protogynous morphs; apparently trees

154 producing only male flowers also occur (Renner et al. 2007). At the study site flowers are

155 produced in May to early June after leaf emergence; female flowers develop into a pair of

156 winged seeds (samaras) during summer that mature and disperse in the fall. In the

157 northern part of its range sugar maple exhibits masting, producing fruit crops at two- to

158 five-year interval depending upon climatic conditions (Godman et al. 1990; Luzadis and

159 Gossett 1996). The production of samaras in years between successive masting events

160 (i.e. non-mast years) is generally negligible (USDA 2008).

161 Bud-break in sugar maple is followed by the expansion of twigs in late May to

162 June (McGee 1986; Watson et al. 1986). Sugar maple twigs may have both determinate

163 and indeterminate patterns of growth depending on age and vigor of the tree as well as

164 position in the crown. While both determinate and indeterminate growth patterns can be

165 observed in the same tree, indeterminate twigs are fairly abundant in the branches of 
166 young vigorous trees, but rare in slow growing older trees (Steingraeber 1982). After the

167 initial flush, sugar maple twigs elongate with a terminal bud located at their ends. The

168 growth in new twigs usually peaks in June or July and culminates in July or August.

169 Sugar maple generally demonstrates apical dominance - a phenomenon whereby the

170 main stem of the branch grows more strongly than side branchlets, particularly at the

171 young age (Bonser and Aarssen 1994).

172 Care was taken to distinguish long shoots from short shoots. Long shoots are the

173 branches with long internodes that grow at the outer edge of the crown, while short

174 shoots are the lateral buds that grow along the long shoot with no distinct internodes

175 (Kozlowski and Clausen 1966). By selecting branches with longer internodes we were

176 able to avoid short shoots, and thus the difficulty of measuring the growth of indistinct 177 internodes.

178

179 Site and tree selection

180 In the summer of 2011, sugar maple trees spanning a wide size range (20-55 $\mathrm{cm} \mathrm{DBH})$,

181 all above the size threshold for reproduction ( 14 cm DBH: Thomas 2010), were located

182 in one stand that had even topography and was accessible by the canopy lift (Scanlift 240

183 manufactured by Kesla of Finland). A total of 31 trees located in close proximity of 184 primary skid trails were sampled, with a roughly equal number of trees in each of four 185 diameter classes: $20-30 \mathrm{~cm}, 30-40 \mathrm{~cm}, 40-50 \mathrm{~cm}$, and $>50 \mathrm{~cm}$ diameter at breast height $186(\mathrm{DBH})$. Among the selected trees, 26 were reproductive (i.e. with samaras) and 5 were 187 non-reproductive (i.e. without samaras). Trees were permanently marked with aluminum 188 tags and diameter at breast height (DBH) measured. The effect of slope position and 
189 topography on the selected variables was assumed to be minimal since the study site was

190 almost flat (slope <2\%).

191

\section{Branch selection and measurement}

193 In 2011, three branches $\sim 1 \mathrm{~cm}$ in diameter were harvested from each tree using an all-

194 terrain canopy lift. The lift was first raised to a pre-determined portion of the crown

195 (upper, mid, or lower), then one of the peripheral branches accessible from that point was

196 chosen at random. Thus, the branches were evenly spaced around the periphery of the

197 upper crown, where most of the seeds are produced. We conducted sampling on the main

198 axis of each branch. A total of 93 branches were harvested from the 31 trees, each with

199 sufficient length to measure rates of branch extension for several years prior to the mast

200 event in 2011. Of these, 30 branches were non-reproductive.

201 Another three branches were sampled from 24 of the same trees in the summer of

2022013 (of which 20 were reproductive and 4 were non-reproductive), for a total additional

20372 branches. Of these, 26 branches were non-reproductive. The second sample included

204 trees with similar range of diameter classes (DBH ranged between 20 and $50 \mathrm{~cm}$ ) as those

205 sampled in 2011. In 2015 (a non-mast year), a more extensive sample of 40-50 branches

206 per tree was collected from 6 additional trees adjacent to the study site that were felled

207 prior to sampling. In all three years sampling took place in July or August when annual

208 extension growth is complete but seeds have not yet dispersed. All harvested branches

209 were tagged, placed in plastic bags, and brought to the laboratory for measurement.

210 The number of samaras (pairs of winged seeds) on the terminal internode of each

211 branch was counted: the terminal internode was identified by finding the distal bud scale 


\section{Page 11 of 37}

212 scar that marks the start of the current year's growth. For this measurement, only the

213 terminal internode of the main axis of each sample branch was considered. Seed

214 production in non-mast years was not assessed, but assumed to be zero since no Acer

215 saccharum seeds were found in a set of $60,0.5-\mathrm{m}^{2}$ litter traps located nearby in the years

216 2008-2010, 2012, 2014 and 2015 (S.C. Thomas, unpublished data).

217 The relationship between reproduction and branch extension was examined at 218 both the level of individual branches and at the level of entire trees. Thus, to enable tree-

219 level analyses, seed production was averaged across all six of the branches collected from

220 trees that were sampled in both 2011 and 2013. For the 7 trees that were not resampled in

221 2013, this average was calculated across the three branches collected in 2011, so the

222 average would be influenced by any difference in seed production between 2011 and 2232013.

224 The length of annual internodes was measured retrospectively to quantify the 225 annual variation in extension rates of each branch $\left(\mathrm{cm}\right.$ year $\left.{ }^{-1}\right)$, including growth during 226 non-mast years. The non-terminal internodes were identified by the presence of 227 successive bud scale (cataphyll) scars representing the start and end of each year's 228 growth. Multiple flushing does occur exceptionally in Acer saccharum (Filewod and

229 Thomas 2014), but is recognizable from bud scale morphology and was not encountered 230 during sampling. Due to the difficulty of correctly identifying older internodes, the 231 measurement of annual extension rates only extended back 3 years prior to the year of 232 collection. Terminal internode lengths were averaged across all six of the branches 233 collected from trees that were sampled in both 2011 and 2013. 


\section{Statistical analysis}

236 Non-linear regression models were used to determine whether extension rates decline as a

237 negative exponential function of seed production and/or stem diameter (Tables 1 and 2).

238 Categorical variables were also used to test whether masting reduces growth in

239 subsequent years: a "pre-/post-mast" categorical variable (0 for 2008-2011, 1 for 2012-

240 2013) allows the intercept of the negative exponential function to be lower after the first

241 mast year (resulting in two parallel curves), as would be expected if the depletion of

242 stored reserves reduces growth in subsequent years. The "first/second mast" categorical

243 variable ( 0 for 2011 and 1 for 2013) allows the slope of the exponential function to be

244 steeper for the second mast year, as would be expected if the depletion of stored reserves

245 reduces growth in subsequent mast years, but not in the intervening years.

246 The regression analyses were conducted at both the level of individual branches

247 and at the level of an entire tree, using the averages taken across all three branches in a 248 tree. Mixed effects models were used for the branch-level analysis, since the observations

249 were not independent. In particular, a random covariance term was included in the

250 mixed-effects models to account for any unmeasured variances associated with nested

251 data (i.e. branches nested within trees) (Pinheiro and Bates 2000).

252 To assess the significance of each predictor variable, reduced models were fit that

253 excluded one or more of the predictor variables. An interaction term between the

254 predictor variables was included in each analysis, but interactions were found to be non-

255 significant (not shown). The best regression model was selected from this set of

256 predictors using Akaike's Information Criteria (AIC). Since the sample size in this study

257 was small $(\mathrm{N}=31)$, AICc (a variant of AIC) was calculated and used instead of AIC to 


\section{Page 13 of 37}

258 correct for small sample size (Burnham and Anderson 1998). Finally, we also conducted

259 a power analysis to assess whether a small sample of branches would suffice to estimate

260 average leader extension throughout the tree crown (see Appendix A).

\section{Results}

263 There was considerable variation in seed production among branches $\left(0-20\right.$ seeds year ${ }^{-1}$

264 with 2.31 standard deviation (S.D.); Fig. 1) and among trees (0-12 seeds year ${ }^{-1}$ with 1.21

265 S.D.; Fig. 2-A). While most trees produced seed in both mast years, some did not: among 266 the 26 trees that set seed in 2011, 4 did not reproduce in 2013, while 3 of the 5 trees that 267 did not reproduce in 2011 set seed in 2013. Average seed production per year was 5.29 268 (S.D. $=0.53)$ in 2011 and $4.31($ S.D. $=0.27)$ in 2013.

269 Branch extension was reduced by $24 \%$ and $36 \%$ (respectively in 2011 and 2013)

270 relative to non-mast years (2010 and 2012, respectively), consistent with the expected

271 negative correlation between growth and seed production (Fig. 3; Table 1). However, 272 masting did not exhibit any relationship with growth in subsequent years (Table 1):

273 neither categorical variable improved the fit of the regression model, indicating that a 274 single intercept and a single slope were sufficient to characterize the relationship between 275 seed production and branch extension. Thus, growth in 2013 was not significantly lower 276 (5.63 \pm 0.33 (S.D.) $\left.\mathrm{cm} \mathrm{year}^{-1}\right)$ than growth in $2011\left(6.71 \pm 0.74\right.$ (S.D.) $\left.\mathrm{cm} \mathrm{year}^{-1}\right)$, even 277 after accounting for the fact that seed production was 23\% lower in 2013 (Fig. 3; Table 278 1).

Branches that produced many seeds grew significantly slower than those that did 280 not (Table 1): terminal internode length decreased from 8 to $3 \mathrm{~cm}$ year $^{-1}$ as seed 
281 production increased from zero to 17 seeds year ${ }^{-1}$ (Fig. 1). Seed production on other

282 branches had no significant effect on a branch's growth rate (Table 1), as indicated by the

283 fact that the most parsimonious model (i.e. the model with the lowest AIC) did not

284 include the average number of seeds $\operatorname{year}^{-1}\left(\mathrm{~S}_{\mathrm{t}}\right)$. These results suggest that the correlation

285 between growth and reproduction is mediated by local resource allocation.

286 Trees that produced many seeds also grew significantly slower than those that did

287 not (Table 2): average internode length (at the whole-tree level) decreased from 10 to 4

$288 \mathrm{~cm}$ year $^{-1}$ as the average number of seeds year ${ }^{-1}$ increased from 0 to 12 (Fig. 2-A). Much

289 of this tree-to-tree variation in seed production is correlated with tree size: the average

290 number of seeds year ${ }^{-1}$ increased from 0 to 8 as stem diameter increased from 20 to $55 \mathrm{~cm}$

291 DBH (Fig. 2-B). Thus, large trees that produce many seeds grew less than small trees that

292 produce fewer seeds: average branch extension declined from about 10 to $4 \mathrm{~cm}^{\text {year }}{ }^{-1}$ as

293 stem diameter and seed production increased from 20 to $55 \mathrm{~cm}$ and 0 to 8 seeds year-1,

294 respectively (Fig. 2-C and 2-B).

295 The most parsimonious model for branch extension growth included seed

296 production, but no other predictors (Table 1). This suggests that it is the ontogenetic

297 increase in reproductive allocation (in mast years), rather than an increase in tree size per

298 se, that drives the decline in branch extension rates. Including a seed production-by-stem

299 diameter interaction did not improve the fit to the data either (not shown), indicating that

300 the slope of the relationship between growth and reproduction (the rate that growth

301 declines with reproduction) is the same for both larger and smaller trees.

302

303 Discussion 
304 This study provides two important insights into the relationships between extension

305 growth and reproduction. First, branch extension varied with the number of seeds

306 produced during mast years (2011 and 2013), such that branches that produced many

307 seeds grew less in that mast year than those that produced few or no seeds. Since most

308 branches produced reproductive structures, this resulted in reduced tree-level average

309 branch extension in mast years. Second, although both seed production and branch

310 extension varied with tree size, the most parsimonious model only included seed

311 production as a predictor of branch extension. These results suggest that increasing

312 reproductive allocation largely determines ontogenetic trends in branch extension growth,

313 with the frequency of mast years controlling growth rates over shorter time scales. The

314 results also suggest that sugar maple branches are somewhat independent from other parts

315 of the tree and that masting does not reduce extension growth in subsequent years (see

316 discussion below).

317 Surprisingly few studies have examined ontogenetic trends in both reproduction

318 and growth of plants, and most of these studies have utilized small plants with short

319 lifespans. Mendez and Obeso (1993) and Worley and Harder (1996) have documented an

320 ontogenetic increase in reproductive allocation and a concomitant decline in growth in

321 two herbaceous perennial species. Our results similarly show a decline in branch

322 extension growth that parallels an increase in reproduction in sugar maple: average

323 branch extension declined from about 10 to $4 \mathrm{~cm}_{\text {year }}{ }^{-1}$ as stem diameter increased from

32420 to $55 \mathrm{~cm}$ (Fig. 2-C), while seed production increased from 0 to 8 seeds year ${ }^{-1}$ (Fig. 2-

325 B). Moreover, we found no statistical effect of tree size on branch extension independent

326 of reproduction. These results are thus consistent with prior studies of herbaceous 


\section{Page 16 of 37}

327 species, and suggest a dominant role of reproductive allocation in driving ontogenetic

328 trends in branch extension growth. Our results are also consistent with data from

329 dioecious tree species, where female trees exhibit a steeper ontogenetic decline in stem

330 growth compared to male trees, associated with higher resource allocation to production

331 of fruits and seeds (Wheelwright and Logan 2004; Thomas 2011).

332 Studies of herbaceous plants also suggest that the extent to which reproduction

333 affects growth is often size-dependent: i.e., the "somatic cost of reproduction" (Bazzaz et

334 al. 2000) increases through ontogeny. In their experimental manipulations of

335 reproduction in two herbaceous perennials (e.g. Plantago rugelii and P. major), Reekie

336 and Bazzaz (1992) found that the reduction in growth per unit of seed production

337 increased with plant size for $P$. major. This observation is consistent with the hypothesis

338 that the costs of reproduction are higher for large plants than for smaller plants because

339 transportation of metabolites to reproductive structures requires more energy due to

340 longer delivery path-lengths (Thomas 2011; Woodruff et al. 2004). However, in the

341 present study we found that the negative correlation between growth and reproduction

342 was size-independent: the seed production-by-stem diameter interaction term was not

343 significant, and thus not consistent with a size-dependent somatic cost of reproduction.

344 Height-dependent increases in hydraulic limitation have been considered as one of

345 the primary drivers of age- or size-related declines in tree growth in contemporary

346 literature (Ryan et al. 2006; Bond et al. 2007). We found that controlling for seed

347 production, stem diameter did not have any effect on branch extension (Table 2),

348 suggesting that size-related biophysical factors (hydraulic limitation) are not responsible

349 for the decline in extension rates as the trees get larger. Indeed, large diameter $(\sim 50 \mathrm{~cm}$ 
350 DBH) trees that had zero seed production (Fig. 2-B) showed identical branch extension

351 rates $\left(\sim 10 \mathrm{~cm} \mathrm{year}^{-1}\right)$ to smaller diameter $(\sim 20 \mathrm{~cm} \mathrm{DBH})$ trees (Fig. 2-C). If there were

352 hydraulic limitation effects of tree size on branch extension, large trees that are non-

353 reproductive would be expected to grow more slowly than small, non-reproductive trees.

354 To further substantiate this inference, we fit two separate regressions for branch

355 extension $\sim$ stem diameter for trees with above and below the average seed production

$356\left(\sim 5\right.$ seeds year $\left.^{-1}\right)$, respectively. Regression analyses result in two nearly parallel lines, one

357 higher and one lower, indicating that trees with lower than the average seed production

358 had higher branch extension and vice versa (Fig. 2-C). Note that although DBH is not a

359 direct measure of transport distance, which could be better reflected by tree height, we

360 found a reasonably high correlation between DBH and tree height $\left(\mathrm{R}^{2}=0.62\right.$, results not

361 shown) in our study system. This led us to choose DBH as a surrogate for transport

362 distance in a tree. Future research could consider tree height as a direct measure of path 363 length.

364 The results presented here are correlational, not experimental: it is thus critical to

365 consider possible alternative explanations to observed patterns. Reduced extension

366 growth with tree size could potentially be driven by senescence (e.g. the progressive

367 decline in the physiological functioning of an organism through time: see Day et al. 2001,

368 2002; Thomas 2010), or by other age-related ontogenetic processes such as increased

369 investment in defenses to combat with pathogens and herbivores (Gross 1972; Tappeiner

370 1969; Boege and Marquis 2005; Loehle 1988). However, these mechanisms would not

371 explain an association between reproduction and extension growth at the branch level,

372 nor a recovery in branch extension rates in non-mast years. The reduction in branch 
373 growth observed in mast years is instead consistent with a wide range of observations that

374 suggest masting involves large changes in resource allocation from vegetative tissues to

375 reproductive structures (Wallace and Rundel 1979; Tuomi et al. 1982; Norton and Kelly

376 1988; Obeso 2002; Monks and Kelly 2006).

377 Annual variation in growth may also reflect confounding variation in

378 environmental factors (temperature and precipitation) that could cause spurious

379 correlations between growth and reproduction (Woodward et al. 1993; Knops et al. 2007;

380 Sanchez-Humanes et al. 2011). For example, in a dendrochronological study of

381 Californian oaks, Knops et al. (2007) found that an apparent negative correlation between

382 acorn output and ring width was driven by opposite responses of growth and reproduction

383 to climatic variables. However, Woodward et al. (1993) reported that environmental

384 factors had positive effects on both growth and reproduction in two conifers (Abies

385 lasiocarpa and Tsuga mertensiana), which enhanced the relationships (negative

386 correlations) between growth and reproduction. A similar pattern was reported by Monks

387 and Kelly (2006) in a study of Nothofagus truncata. Moreover, a meta-analysis of similar

388 studies found no difference in correlations between ring-widths and reproductive

389 measures based on direct correlations, and those correcting for climate variables (Thomas

390 2011).

391 The present study focuses on branch extension growth, rather than growth of the

392 main stem or biomass increment of the whole tree. From the perspective of tree resource

393 access and competition, crown extension is critical, determining light interception and

394 lateral capture of canopy gaps (Hibbs 1982; Cole and Lorimer 2005; Purves et al. 2007;

395 Thorpe et al. 2010). Crown extension depends not only on branch extension, but also 
396 branch dieback, which we have recently found to increase with tree size in Acer

397 saccharum (Hossain and Caspersen 2012). Thus, while we did not directly examine

398 whole-tree diameter or biomass increment in the present study, it seems likely that the net

399 decrease in crown extension would ultimately contribute to decreased whole-tree carbon

400 gain. It is thus reasonable to hypothesize that reduced branch extension growth goes

401 along with reduced growth of main stems.

402 Masting appeared to have no influence on extension rates in subsequent years, as

403 branch extension rebounded immediately after masting to a level that is similar to pre-

404 mast extension rates (Fig. 3). This result contrasts with some prior findings from

405 dendrochronological studies that masting results in both reduced growth in the mast year

406 and a lagged growth reduction in subsequent years (Kelly and Sork 2002; Monks and

407 Kelly 2006; Silvertown and Dodd 1999). The lack of a lagged growth response in the

408 present study suggests that branch extension in sugar maple does not depend upon

409 resources stored over previous years (Monks and Kelly 2006). As a result, ontogenetic

410 decline in growth may be dependent upon the frequency of masting, which generally

411 increases monotonically with tree size (Thomas 2011; Thomas 2011 Thomas 1996; Kelly

412 and Sork 2002; Obeso 2002; Genet et al. 2010). Over shorter time scales, however,

413 declining growth may not be observed given variability in masting.

414 In addition we found that the extension rate of a branch was influenced by the

415 seed production of the branch itself (Fig. 1), but not by seed production on other branches

416 (Table 1), suggesting that the trade-off between growth and reproduction is mediated by

417 resources that are allocated locally. This trade-off is also manifest at the tree level (Fig. 2)

418 simply because the average extension rate of a tree is proportional to the fraction of 
419 reproductive branches (regardless of their level of integration), and the amount of

420 reproduction per branch. These findings suggest some degree of independence of

421 individual branches from other parts of the tree in terms of carbon translocation (Sprugel

422 et al. 1991; Despland and Houle 1997; Yasumura 2006).

423 Reproductive costs have long been considered of central importance in

424 understanding life-history evolution (Stearns 1992), but the physiological mechanisms

425 that result in tradeoffs between reproduction and growth have only recently received

426 closer scrutiny (Harshman and Zera 2007). In short-lived plant species, reproductive

427 effects on growth have not only been recognized to be pervasive, but also to have

428 practical significance for enhancing growth and yield by reducing reproductive costs via

429 genetic engineering (Mouradov and Teasdale 1999; Strauss et al. 1995). The emphasis in

430 the literature on biophysical constraints on tree growth has likely contributed to a lack of

431 research on reproductive costs and possible applications in trees (Strauss et al. 1995;

432 Brunner et al. 2007).

433

434 Author contribution statement SMYH, JPC and SCT originally conceptualized the

435 study. SMYH, JPC, and SCT designed the sampling and data collection methods. SMYH

436 conducted fieldwork, including measurement of branch extension growth and seed

437 production, and performed the statistical analyses and result interpretation with JPC and

438 SCT. SMYH wrote the initial draft of the manuscript, which was revised by JPC and

439 SCT. 
441 Acknowledgements We thank Haliburton Forest and Wildlife Reserve for their support

442 to conduct this research, Philip Rudz and Lazar Pavlovic for their field assistance, as well

443 as Tomasz Gradowski for providing lift training. We also thank Tat Smith of the

444 University of Toronto and Bill Cole of the MNR, Ontario for their comments on an

445 earlier version of this manuscript.

446

447 Compliance with ethical standards

448

449 Conflict of interest The authors declare that they have no conflict of interest.

\section{$451 \quad$ References}

452 Barnard HR, Ryan MG (2003) A test of the hydraulic limitation hypothesis in fast453 growing Eucalyptus saligna. Plant, Cell and Env 26: 1235-1245

454 Bazzaz FA, Ackerly DD, Reekie EG (2000) Reproductive allocation and reproductive 455 effort in plants. In: Fenner M (ed) Seeds: the ecology of regeneration in plant 456 communities, 2nd edn. CAB International, Oxford, pp 1-37

457 Boege K, Marquis RJ (2005) Facing herbivory as you grow up: the ontogeny of 458 resistance in plants. Tren Ecol Evol 20: 520-526

459 Bond BJ, Czarnomski NM, Cooper C et al (2007) Developmental decline in height 460 growth in Douglas-fir. Tree Physio 27: 441-453

461 Bond BJ, Ryan MG (2000) Comment on 'Hydraulic limitation of tree height: a critique' 462 by Becker, Meinzer \& Wullschleger. Funct Ecol 14: 137-140

463 Bonser SP, Aarssen LW (1994) Plastic allometry in young sugar maple (Acer 
Page 22 of 37

saccharum): adaptive responses to light availability. Am J Bot 81: 400-406

465 Brunner AM, Li JY, DiFazio SP et al (2007) Genetic containment of forest plantations.

466 Tree Gen Geno 3: 75-100

467 Burnham KP, Anderson DR (1998) Model Selection and Inference: A Practical

468 Information-Theoretic Approach. Springer-Verlag, New York

469 Choi J, Lorimer CG, Vanderwerker J et al (2001) A crown model for simulating long

$470 \quad$ term stand and gap dynamics in northern hardwood forests. For Ecol Manage 152:

$471 \quad 235-258$

472 Cole WG, Lorimer CG (2005) Probabilities of small-gap capture by sugar maple

473 saplings based on height and crown growth data from felled trees. Can J For Res

$474 \quad 35: 643-655$

475 Despland E, Houle G (1997) Climate influences on growth and reproduction of

476 Pinus banksiana (Pinaceae) at the limit of the species distribution in Eastern North

$477 \quad$ America. Am J Bot 84: 928-937

478 Dick JM, Leakey RRB, Jarvis PG (1990) Influence of female cones the

479 vegetative growth of Pinus contorta trees. Tree Physio 16: 151-163

480 Environment Canada (2004). Canadian Climate Normals 1971-2000. Web page accessed 481 in 2005.

482 Filewod B, Thomas SC (2014) Impacts of a spring heat wave on canopy processes in a 483 northern hardwood forest. Glob Chan Bio 20: 360-371

484 Fox JF, Stevens GC (1991) Costs of reproduction in a willow: experimental responses vs. 485 natural variation. Ecology 72: 1013-1023 
486 Genet H, Bréda N, Dufrêne E (2010) Age-related variation in carbon allocation at tree

487 and stand scales in beech (Fagus sylvatica L.) and sessile oak (Quercus petraea

488 (Matt.) Liebl.) using a chronosequence approach. Tree Physio 30: 177-192

489 Godman RM, Yawney HW, Tubbs CH (1990) Acer saccharum (Marsh.) sugar maple.

490 Silvics of North America. Vol. 2. Hardwoods Agric. Handb. 654 (Burns, Russell M.;

491 Honkala, Barbara H., technical coordinators), Washington DC, U.S. Department of

$492 \quad$ Agriculture, Forest Service, pp 78-91

493 Gower ST, McMurtrie RE, Murty D (1996) Aboveground net primary production decline

$494 \quad$ with stand age: potential causes. Tren Ecolog Evol Res 11: 378-382

495 Gross HL (1972) Crown deterioration and reduced growth associated with excessive seed

496 production by birch. Can J Bot 50: 2431-2437

497 Harshman LG, Zera AJ (2007) The cost of reproduction: the devil in the details. Tren

$498 \quad$ Ecol Evol 22: 80-86

499 Hibbs DE (1982) Gap dynamics in a hemlock-hardwood forest. Can J For Res 12: 522-

$500 \quad 527$

501 Hossain SMY, Caspersen JP (2012) In-situ measurement of twig dieback and regrowth in

502 mature Acer saccharum trees. For Ecol Manage, 270: 183-188

503 Iwasa Y (2000) Dynamic optimization of plant growth. Evol Ecol Res 2: 427-455

504 Iwasa Y, Cohen D (1989) Optimal growth schedule of a perennial plant. Am Nat 133:

$505 \quad 480-505$

506 Kelly D, Sork VL (2002) Mast seeding in perennial plants: why how where? Ann Rev

$507 \quad$ Ecol Sys 33: 427-447

508 King D, Roughgarden J (1982) Graded allocation between vegetative and 
reproductive growth for annual plants in growing seasons of random length.

$510 \quad$ Theor Pop Biol 21: 1-16

511 Knops JMH, Koenig WD, Carmen WJ (2007) Negative correlation does not imply a

512 tradeoff between growth and reproduction in California oaks. Proc the Nat Aca Sci,

$513 \quad$ USA 104: 16982-16985

514 Koch GW, Sillett SC, Jennings GM et al (2004) The limits to tree height. Nature 428:

$515 \quad 851-854$

516 Kozlowski TT, Clausen JJ (1966) Shoot growth characteristics of heterophyllous

$517 \quad$ woody plants. Can J Bot 44: 827-843

518 Kutsch WL, Wirth C, Kattge K et al (2009) Ecophysiological characteristics of mature

519 trees and stands - consequences for old-growth forest productivity. In: Wirth C,

520 Gleixner G, Heimann M (eds) Old growth forests: function, value and fate,

$521 \quad$ Springer, Berlin, pp 57-69

522 Loehle C (1988) Tree life-history strategies: the role of defenses. Can J For Res 18: 209-

52322

524 Luzadis VA, Gossett ER (1996) Sugar Maple. In: Lassoie, JP, Luzadis VA, Grover DW

525 (eds) Forest Trees of the Northeast, Cooperative Extension Bulletin 235, Cornell

526 Media Services, University of Cornell, pp 157-166

527 McGee CE (1986) Budbreak for Twenty-Three Upland Hardwoods Compared Under

$528 \quad$ Forest Canopies and in Recent Clearcuts. For Sci 32(4): 924-935

529 Mendez M, Obeso JR (1993) Size-dependent reproductive and vegetative allocation

$530 \quad$ in Arum italicum (Araceae). Can J Bot 71: 309-314 
531 Monks A, Kelly D (2006) Testing the resource-matching hypothesis in the mast seeding

532 tree Nothofagus truncata (Fagaceae). Aust Ecol 31: 366-375

533 Mouradov A, Teasdale RD (1999) Genetic engineering of reproductive incompetence in $534 \quad$ radiata pine. Protoplasma 208 (1-4): 13-17

535 Norton DA, Kelly D (1988) Mast seeding over 33 years by Dacrydium cupressinum

536 Lamb (rimu) (Podocarpaceae) in New Zealand: the importance of economies of

$537 \quad$ scale. Func Ecol 2: 399-408

538 Obeso JR (2002) The costs of reproduction in plants. New Phyto 155: 321-348

539 Pinheiro JC, Bates DM (2000) Mixed-effects models in S and S-PLUS. Springer, $540 \quad$ New York

541 Purves DW, Lichstein JW, Pacala SW (2007) Crown plasticity and competition for 542 canopy space: a new spatially implicit model parameterized for 250 North $543 \quad$ American tree species. PLoS One 2: e870

544 Reekie EG, Bazzaz FA (1992) Cost of reproduction as reduced growth in genotypes of 545 two congeneric species with contrasting life histories. Oecologia 90: 21-26

546 Renner SS, Beenken L, Grimm GW et al (2007) The evolution of dioecy, 547 heterodichogamy, and labile sex expression in Acer. Evolution 61: 2701-2719

548 Ryan MG, Phillips N, Bond BJ (2006) The hydraulic limitation hypothesis revisited. $549 \quad$ Plant Cell Env 29: 367-381

550 Ryan MG, Binkley D, Fownes JH (1997) Age-related decline in forest productivity:

$551 \quad$ Pattern and Process. Adv Ecol Res 27: 214-262

552 Sanchez-Humanes B, Sork VL, Espelta JM (2011) Trade-offs between vegetative growth 553 and acorn production in Quercus lobata during a mast year: the relevance of crop 


\section{Page 26 of 37}

size and hierarchical level within the canopy. Oecologia 166: 101-110

555 Silvertown J, Dodd M (1999) The Demographic Cost of Reproduction and Its

556 Consequences in Balsam Fir (Abies balsamea). Am Nat 154: 321-332

557 Sprugel DG, Hinckley TM, Schaap W (1991) The theory and practice of branch

558 autonomy. Ann Rev Ecol Sys 22: 309-334

559 Stearns SC (1992) The Evolution of Life Histories. Oxford University Press. Oxford

560 Steingraeber DA (1982) Heterophylly and Neoformation of leaves in sugar maple (Acer

$561 \quad$ saccharum). Am J Bot 69(8): 1277-1282

562 Stephenson NL et al (2014) Rate of tree carbon accumulation increases continuously

$563 \quad$ with tree size. Nature 507: 90-93

564 Strauss SH, Rottmann WH, Brunner AM et al (1995) Genetic engineering of reproductive

$565 \quad$ sterility in forest trees. Mol Breed 1: 5-26

566 Tappeiner JC (1969) Effect of cone production on branch, needle, and xylem ring

567 growth of Sierra Nevada Douglas-fir. For Sci 15: 171-174

568 Thomas SC (2011) Age-related changes in tree growth and functional biology: the role

569 of reproduction. In: Meinzer FC, Dawson T, Lachenbruch BJ (eds) Invited

570 chapter for Size- and Age-Related Changes in Tree Structure and Function, Tree

$571 \quad$ Physiology, Springer-Verlag, pp 33-64

572 Thomas SC (2010) Photosynthetic capacity peaks at intermediate size in temperate

573 deciduous trees. Tree Physio 30: 555-573

574 Thomas SC (1996) Reproductive allometry in Malaysian rain forest trees: biomechanics

$575 \quad$ versus optimal allocation. Evol Ecol 10: 517-530

576 Thomas SC, Martin AR, Mycroft EE (2015) Tropical trees in a wind-exposed island 
ecosystem: height-diameter allometry and size at onset of maturity. J Ecol 103:

579 Thorpe HC, Astrup R, Trowbridge A et al (2010) Competition and tree crowns: a neighborhood analysis of three boreal tree species. For Ecol Manage 259: 15861596

582 Tuomi J, Neimela P, Mannila R (1982) Resource allocation on dwarf shoots of birch

583 (Betula pendula) - reproduction and leaf growth. New Phyto 91: 483-487

584 United States Department of Agriculture (USDA) (2008) Woody Plant Seed manual.

$585 \quad$ USDA Forest Service, Agriculture Handbook 727

586 Wallace CS, Rundel PW (1979) Sexual dimorphism and resource allocation in male $587 \quad$ and female shrubs of Simmondsia chinensis. Oecologia 44: 34-39

588 Watson GW, Himelick EB, Smiley ET (1986) Twig growth of eight species of 589 shade trees following transplanting. J Arbori 12(10): 241-245

590 Weiner J, Thomas SC (2001) The nature of tree growth and the age-related decline in forest productivity. Oikos 94: 374-376

592 Wheelwright NT, Logan BA (2004) Previous-year reproduction reduces photosynthetic capacity and slows lifetime growth in females of a neotropical tree. Proc Nat Aca Sci USA 101: 8051-8055

595 Woodruff DR, Bond BJ, Meinzer FC (2004) Does turgor limit growth in tall trees? Plant Cell Env 27: 229-236

597 Woodward A, Silsbee DG, Schreiner EG et al (1993) Influence of climate 598 on radial growth and cone production in subalpine fir (Abies lasiocarpa) and mountain hemlock (Tsuga mertensiana). Can J For Res 24: 1133-1143 
Page 28 of 37

600 Worley AC, Harder LD (1996) Size-dependent resource allocation and costs of 601 reproduction in Pinguicula vulgaris (Lentibulariaceae). J Ecol 84: 195-206

602 Yasumura Y, Hikosaka K, Hirose T (2006) Resource allocation to vegetative and

603 reproductive growth in relation to mast seeding in Fagus crenata. For Ecol

$604 \quad$ Manage 229: 228-233

605 Yoder BJ, Ryan MG, Waring RH et al (1994) Evidence of reduced photosynthetic rates

606 in old trees. For Sci 40: 513-527

607 


\section{Figures}

\section{Fig. 1}

610 Seed production and extension rates of all internodes $(n=165)$, including non-terminal

611 internodes formed in non-mast years. The trend line is a negative exponential function

612 that was fit to the data using mixed-effects regression. This model was selected as the

613 most parsimonious because it had the lowest $\mathrm{AIC}$ score $(\Delta \mathrm{AIC}=0$, Table 1$)$. The black

614 and white circles represent terminal internodes formed in mast years (2011 and 2013,

615 respectively), while those in grey represent non-terminal internodes formed in non-mast

616 years (2008-2010 and 2012). Note that non-terminal internodes had no seed set.

\section{Fig. 2}

619 Average seed production and branch extension of each sugar maple tree, including all the

620 terminal internodes collected in 2011 and $2013(\mathrm{n}=31$; 2-A). Data points are means

621 taken across the terminal internodes of 3 or 6 branches per tree. The trend line is a

622 negative exponential function that was fit to the data using standard regression (Table 2).

623 This model was selected as the most parsimonious because it had the lowest AIC score

$624(\triangle \mathrm{AIC}=0$, Table 1$)$. The dotted lines (above and below the solid line) represent

625 regression trends that were fit to a subset of the data from trees that are below and above, 626 respectively, the average seed production $\left(\sim 5\right.$ seeds year $\left.{ }^{-1}\right)$. In both cases, the negative

627 exponential model was significant (Table S1), and the lines are parallel, indicating that, 628 regardless of stem diameter, trees with lower than the average seed production had higher 629 branch extension, and vice versa. 


\section{Page 30 of 37}

\section{$631 \quad$ Fig. 3}

632 Annual variation in the extension rate of all internodes. The years 2011 and 2013 were

633 mast years. Bars on each data point indicate \pm two standard deviations.

634

635 
Page 31 of 37

636 Fig. 1

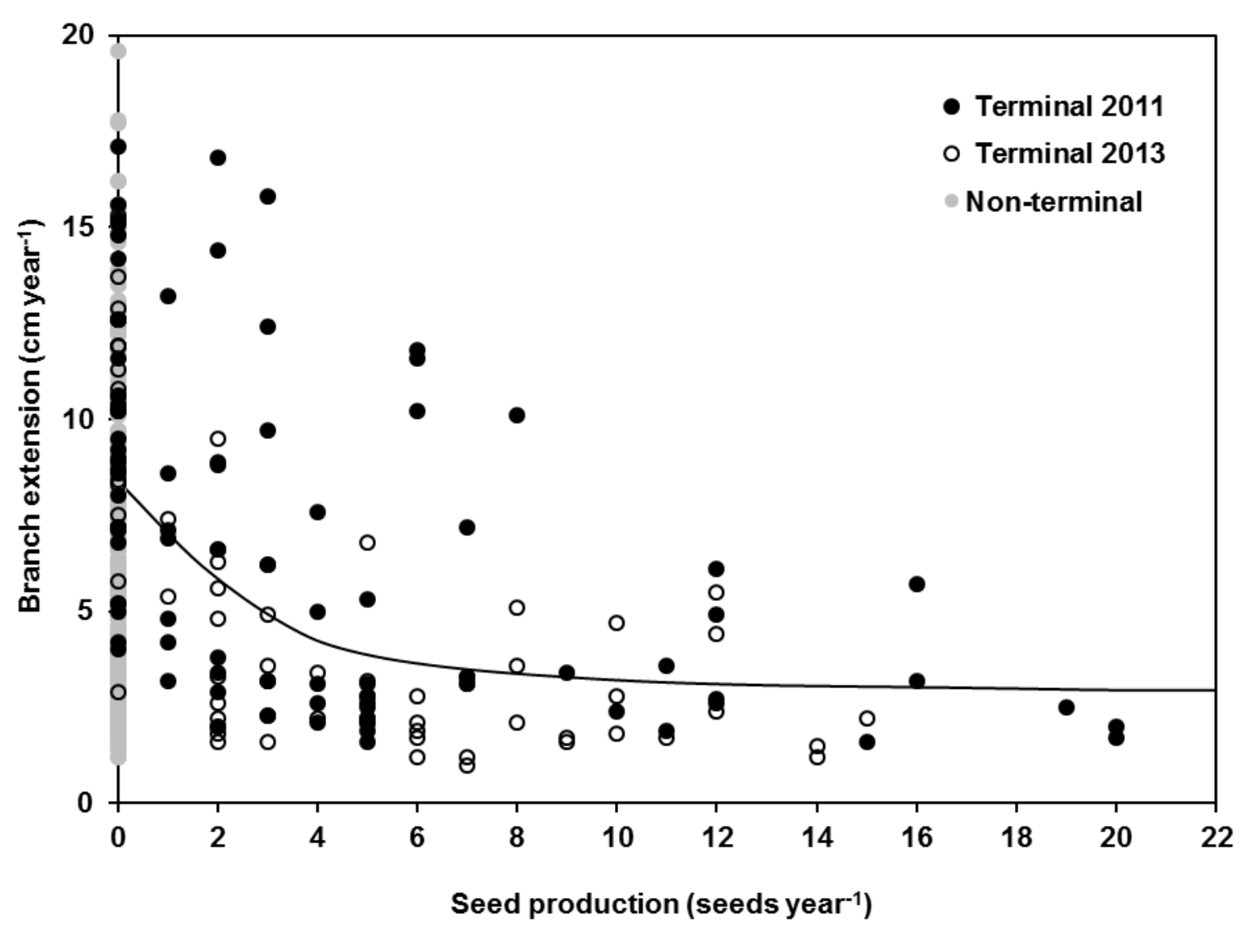

637

638 
Page 32 of 37

Fig. 2

640

641

642

643

644

645

646

647

648

649

650

651

652

653

654

655

656
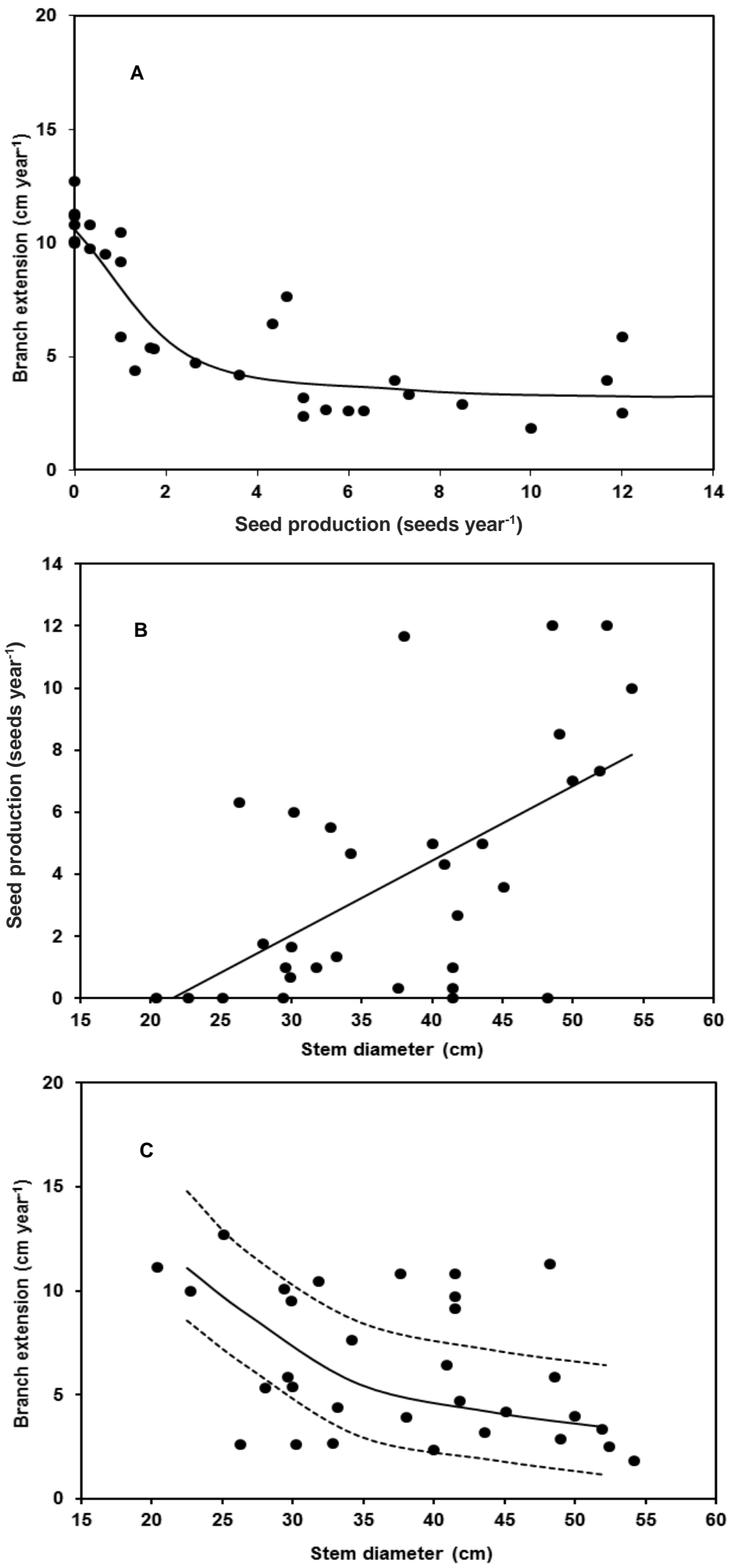
Page 33 of 37

$657 \quad$ Fig. 3

658

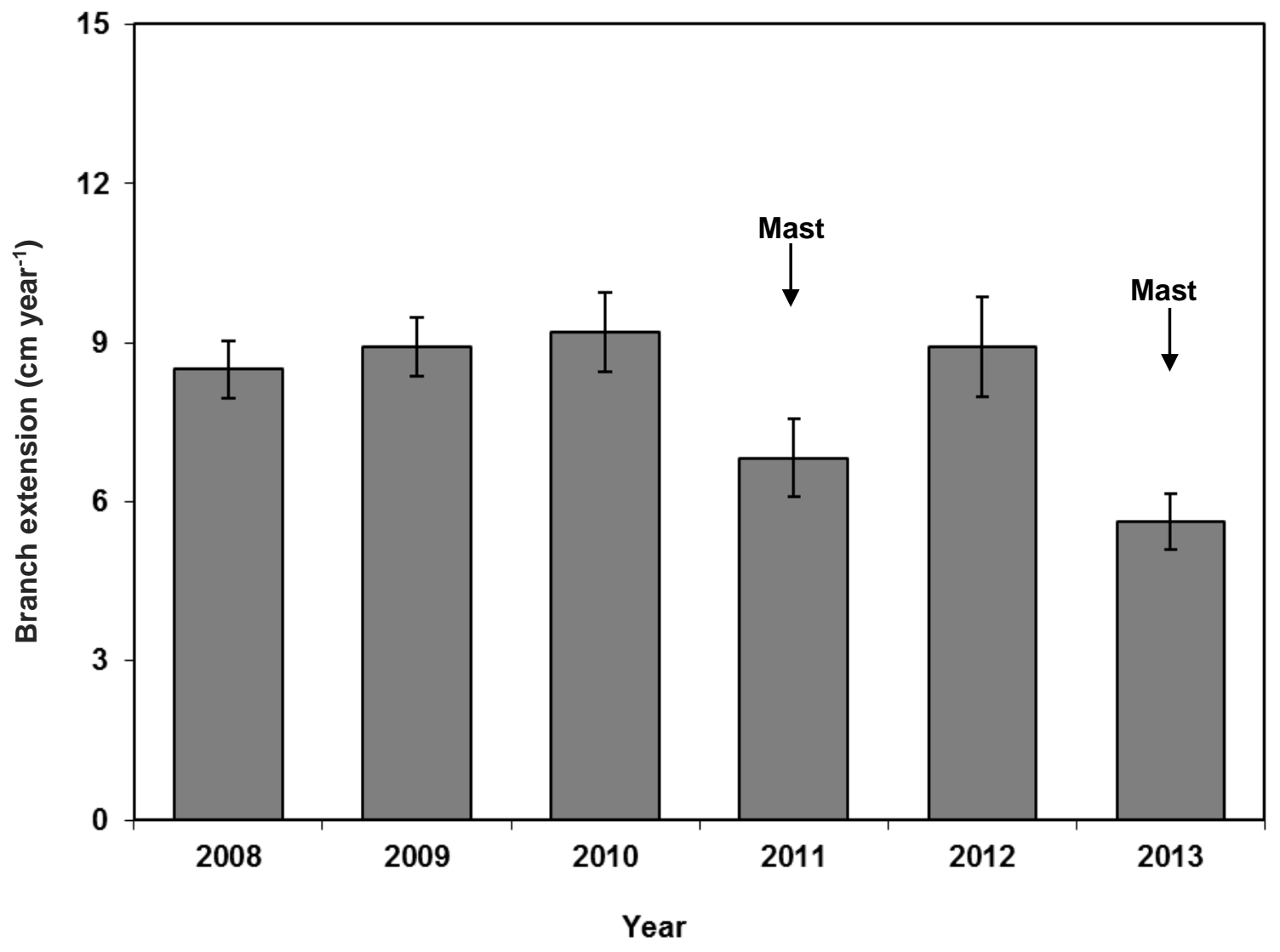

659 
Page 34 of 37

\section{Tables}

661 Table 1 Branch-level analyses of the relationship between seed production and branch

662 extension. $\mathrm{G}_{\mathrm{b}}$ is the extension rate of an individual branch, $\mathrm{S}_{\mathrm{b}}$ is the seed production of

663 the branch, and $S_{t}$ is the seed production averaged across all branches sampled in a tree.

664 D1 (pre-/post-mast) and D2 (first/second mast) are categorical variables used to test

665 whether masting reduces growth in subsequent years (see methods).

\begin{tabular}{lcc}
\hline \multicolumn{1}{c}{ Model } & AICc & $\Delta$ AICc \\
\hline$G_{b}=\varphi+\alpha e^{\left(-\beta S_{b}\right)}$ & 2597.51 & 0.00 \\
\hline$G_{b}=\varphi+\alpha e^{\left(-\beta S_{b-\gamma} S_{t}\right)}$ & 2.36 \\
\hline$G_{b}=\varphi+\alpha e^{\left(-\beta S_{b-\theta D B H}\right)}$ & 2599.87 & 2.38 \\
\hline$G_{b}=\varphi+\alpha e^{\left(-(\alpha+\delta D 1) S_{b}\right)}$ & 2599.89 & 2.61 \\
\hline$G_{b}=\varphi+(\alpha+\lambda D 2) e^{\left(-\beta S_{b}\right)}$ & 2600.12 & 4.54 \\
\hline$G_{b}=\varphi+\alpha e^{(-\theta D B H)}$ & 2602.05 & 6.60 \\
\hline$G_{b}=\varphi$ & & 6.65
\end{tabular}

666

667

668

669

670

671

672 
Page 35 of 37

673 Table 2 Tree-level analyses of the relationship between seed production and branch

674 extension. $G_{t}$ is the average extension rate of all the branches in a tree, and $S_{t}$ is the 675 average seed production of all the branches in a tree.

\begin{tabular}{lcc}
\hline \multicolumn{1}{c}{ Model } & AICc & UAICc \\
\hline$G_{t}=\varphi+\alpha e^{\left(-\gamma S_{t)}\right.}$ & 126.31 & 0.00 \\
\hline$G_{t}=\varphi+\alpha e^{\left(-\gamma S_{t-\theta D B H)}\right.}$ & 128.89 & 2.58 \\
\hline$G_{t}=\varphi+\alpha e^{(-\theta D B H)}$ & 131.26 & 4.95 \\
\hline$G_{t}=\varphi$ & 134.48 & 8.17
\end{tabular}

676

677

678

679

680

681

682

683

684

685

686

687

688

689

690 
Page 36 of 37

Appendices

\section{Appendix A}

693 A power analysis was conducted to determine the minimum sample size per tree in order

694 to detect a significant trend. First we pulled out data for the largest and smallest tree, and

695 then resampled with replacement to calculate proportion of statistically significant

696 comparisons by a simple t-test (results not shown). This analysis showed that a sample of

697 3-6 branches would provide one a 10\% chance of detecting a significant trend, with an

698 assumed effect size value of 0.5 (coefficient of determination). However, the minimum

699 sample size should have been $\sim 40$ to achieve a statistical power of 0.8 .

700

701 Table S1 Tree-level analyses of the relationship between seed production and branch

702 extension, conducted using a subset of the data from trees that are below and above,

703 respectively, the average seed production $\left(\sim 5\right.$ seeds year $\left.{ }^{-1}\right) . \mathrm{G}_{\mathrm{t}}$ is the average extension

704 rate of all the branches in a tree, and $S_{t}$ is the average seed production of all the branches

705 in a tree.

\begin{tabular}{lcc}
\hline \multicolumn{1}{c}{ Model } & AICc & AAICc \\
\hline$G_{t}=\varphi+\alpha e^{\left(-\gamma S_{t)}\right.}$ & 126.31 & 0.00 \\
\hline$G_{t}=\varphi$ & 134.48 & 8.17 \\
\hline$G_{t}=\varphi+\alpha e^{\left(-\gamma S_{t)}\right.}$ & 126.31 & 0.00 \\
\hline$G_{t}=\varphi$ & 134.48 & 8.17 \\
\hline
\end{tabular}


Page 37 of 37

708 